\title{
Raising Healthy Children: Milk and Egg Allergies ${ }^{1}$
}

\author{
Jonathan Holzinger, Karla Shelnutt, and Gail Kauwell ${ }^{2}$
}

Milk and eggs are familiar, nutritious foods that most children enjoy, but these foods can cause problems for children with milk and egg allergies. If your child is allergic to milk or eggs, you need to consider steps you and your child can take to avoid these foods. You can do this by identifying ingredients that can cause an allergic reaction and finding milk-free and egg-free recipes. Also, you need to make sure your child gets enough of the proper nutrients, especially if certain foods are removed from his or her diet. Fortunately, many children outgrow milk and egg allergies by the age of five if they avoid offending foods when they are young (A.D.A.M. Medical Encyclopedia, 2012). This publication will help you learn more about milk and egg allergies and how to make sure your allergic child stays safe.

\section{What Is a Food Allergy?}

An estimated 5.9 million children in the United States suffer from food allergies (Gupta et al., 2011). According to the American Academy of Allergy, Asthma \& Immunology, a food allergy occurs when a food protein triggers an abnormal response by the immune system. Eating a certain food may trigger the sudden release of chemicals that can cause symptoms of an allergic reaction. These symptoms may be minor (e.g., rash, hives, itchy skin, wheezing, or vomiting) or they may be more severe (e.g., anaphylactic reaction). An anaphylactic reaction can cause breathing problems, abdominal pain, rapid pulse, and loss of consciousness. If you think your child is having an anaphylactic reaction, the child should be given an emergency epinephrine shot, and you should immediately take the child to the emergency room (American Academy of Allergy, Asthma \& Immunology, 2012).

\section{Milk Allergy}

A milk allergy is an abnormal immune response to products that contain milk proteins. Cow's milk is the most common cause of a milk allergy, but milk from sheep, goats,

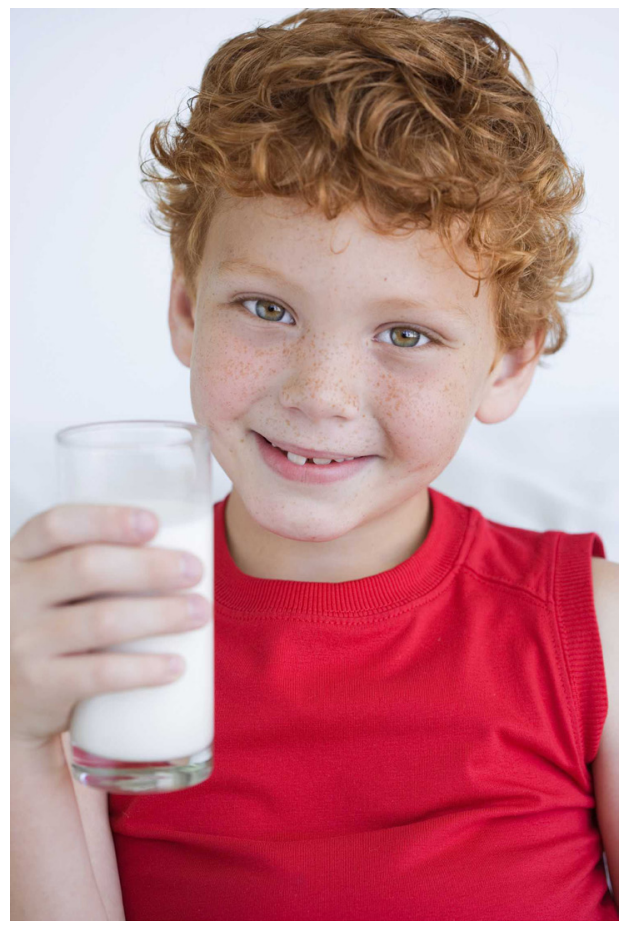

Figure 1. Although many children enjoy milk, be aware that some children can be allergic to milk and milk products. Credits: Jupiterimages

1. This document is FCS80020, one of a series of the Department of Family, Youth and Community Sciences, Florida Cooperative Extension Service, Institute of Food and Agricultural Sciences, University of Florida. Original publication date February 2013. Please visit the EDIS website at http://edis. ifas.ufl.edu.

2. Jonathan Holzinger, dietetic intern, Food Science and Human Nutrition Department; Karla Shelnutt, PhD, RD, assistant professor, Department of Family, Youth and Community Sciences; and Gail Kauwell, PhD, RD, LD/N, professor, Food Science and Human Nutrition Department; Florida Cooperative Extension Service, Institute of Food and Agricultural Sciences, University of Florida, Gainesville, FL 32611. 
and buffalo can also cause a reaction. Usually an allergy to milk develops within an infant's first year; however, most children who have a milk allergy will outgrow it in a few years (Asthma and Allergy Foundation of America, 2005b; Food Allergy Initiative, 2012).

Two main proteins in cow's milk can cause an allergic reaction. These proteins are called casein and whey. A child with a milk allergy can be allergic to only one of these proteins or both of them. Casein and whey also can be found in processed foods such as frozen dinners, hot dogs, and seasonings used for savory snack foods such as potato chips.

\section{Ingredients that Contain Milk Proteins}

Children with a milk allergy must completely avoid foods that contain milk, including all dairy products and foods processed with milk. Also, read the ingredients list and avoid foods with the following ingredients (Food Allergy Initiative, 2012):

- Casein

- Lactalbumin

- Lactoglobulin

- Lactulose

- Hydrolysates (casein, whey)

- Lactalbumin phosphate

- Lactoferrin

- Whey

Examples of the types of foods that may contain milk or milk products include the following (Phillips, Chang, Chalmers, \& Foster, 2012):

- Cake mixes

- Bread products

- Candy

- Cheese

- Salad dressing

- Seasonings and condiments

- Boxed cereals

- Crackers

- Deli meats

\section{Severity of Milk Allergy}

The sensitivity and severity of a milk protein allergy can vary greatly from child to child. The allergic reaction that occurs depends on what the child can tolerate. Some children have a severe reaction after consuming only a small amount of milk, while others have only a mild reaction after consuming a moderate amount of milk or milk products. The amount and types of milk products a child with a milk

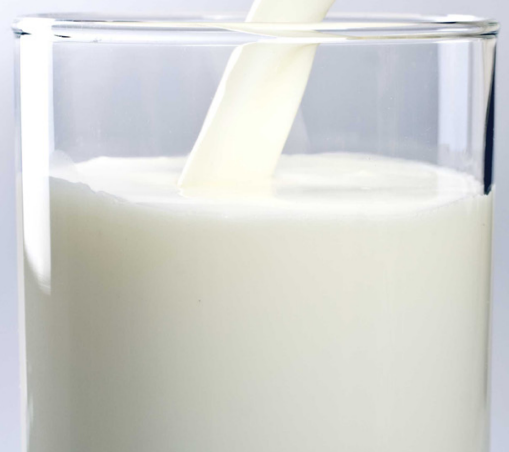

Figure 2. Children who are allergic to milk should avoid all foods that contain milk, including any foods made with milk or milk products. Credits: iStockphoto

allergy can consume vary depending on the severity of his or her allergy (Food Allergy Initiative, 2012).

\section{Replacing Lost Nutrients}

Milk and dairy products are important sources of calcium and vitamin $\mathrm{D}$. If your child has a milk protein allergy, he or she should consume other foods rich in or fortified with these nutrients, or your child can take a supplement. Foods high in calcium include green leafy vegetables (e.g., collard greens and spinach), fortified soy products, and orange juice fortified with calcium and vitamin D. Although soy milk is a popular alternative to milk from animal sources, some people may have an allergic reaction to soy. Soy allergies are more common in infants, but the majority of infants outgrow it by the age of two.

\section{Egg Allergy}

An egg allergy is another common food allergy (Eggesbo, Botten, Halvorsen, \& Magnus, 2001). Most egg allergy reactions occur in children when they are 6 months to 15 months, or when they are given an egg for the first time. Many children develop a tolerance to eggs and outgrow their egg allergy when they are between 2-4 years old (Boyano-Martinez, Garcia-Ara, Diaz-Pena, \& MartinEsteban, 2002). In some cases, an egg allergy continues into adulthood.

\section{What Causes Egg Allergies?}

An egg allergy is caused by an overreaction of the immune system in response to eating eggs. Both the egg yolk and egg white contain proteins that can cause an allergic reaction, but allergies to egg whites are more common (Asthma and Allergy Foundation of America, 2005a). Allergic reactions 


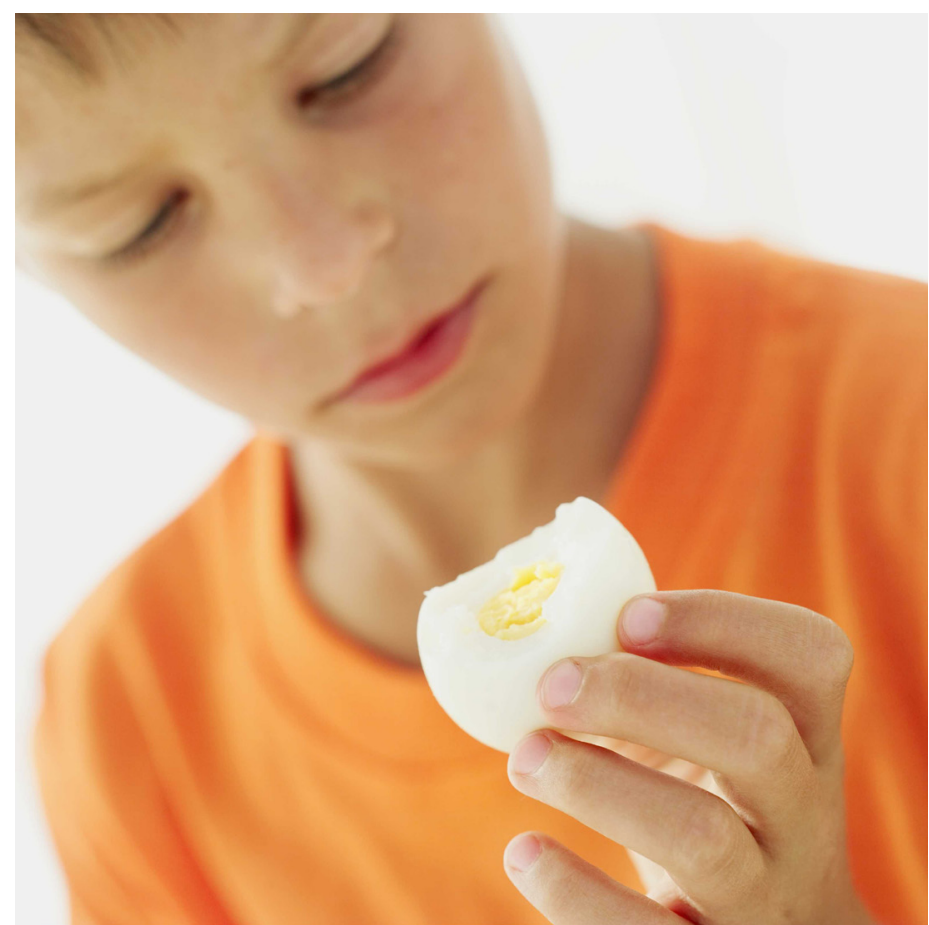

Figure 3. Children can also be allergic to eggs. An allergic reaction to eggs usually occurs in children when they are between 6-15 months. Credits: Stockbyte

to eggs can occur within minutes to hours after eating eggs or foods containing eggs.

\section{Ingredients that Contain Egg}

Many foods contain eggs and egg products.

The following ingredients contain egg protein and should be completely avoided if your child has an allergy to eggs (Asthma and Allergy Foundation of America, 2005a):

- Albumin

- Globulin

- Lecithin

- Livetin

- Lysozyme

- Ovalbumin or ovoglobulin (or any other ingredient that starts with "ova" or "ovo")

- Silici albuminate

- Simplesse

- Vitellin

\section{Foods that May Contain Egg}

If your child has an egg allergy or you suspect that he or she has an egg allergy, read labels to see if foods contain egg or ingredients made with eggs. If they do, avoid them. Examples of foods that may contain egg or egg products include the following (Asthma and Allergy Foundation of America, 2005):

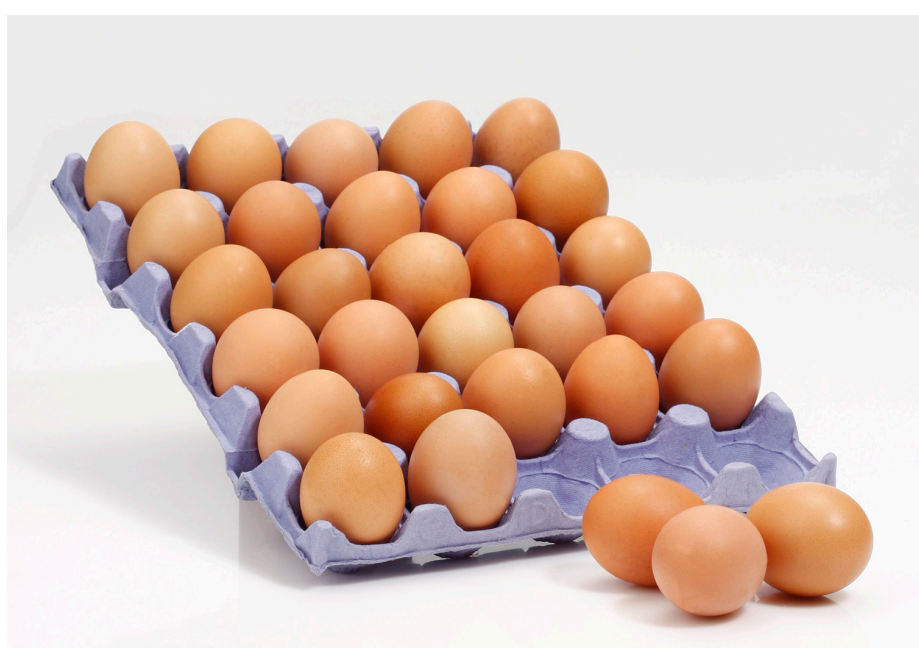

Figure 4. Children who are allergic to eggs should not eat eggs or any food that contains eggs. See the lists in this publication for examples of foods that contain eggs and egg products. Credits: iStockphoto

- Cake flour

- Candies

- Cookies

- Frosting

- Mayonnaise

- Meatloaf

- Meatballs

- Noodle soups/egg noodles

- Processed meats

- Pudding, custard, or flan

- Root beer

- Salad dressings

- Spaghetti

\section{Reading Food Labels}

Always check the food label to see if a product contains milk, egg, or other common allergens. A labeling law called the Food Allergen Labeling and Consumer Protection Act of 2004 makes it easier to identify foods that contain common food allergens. This law requires that food labels on products manufactured after January 2006 clearly identify the source of ingredients derived from eight major food allergens (including egg and milk). The major food allergen is listed on the label in one of three ways (U.S. Food and Drug Administration, 2010):

\section{In the ingredients list.}

2. After the name of the ingredient derived from the allergen. For example: albumin (egg).

3. Below the ingredient list in a "contains" statement. For example: Contains: milk, egg. 


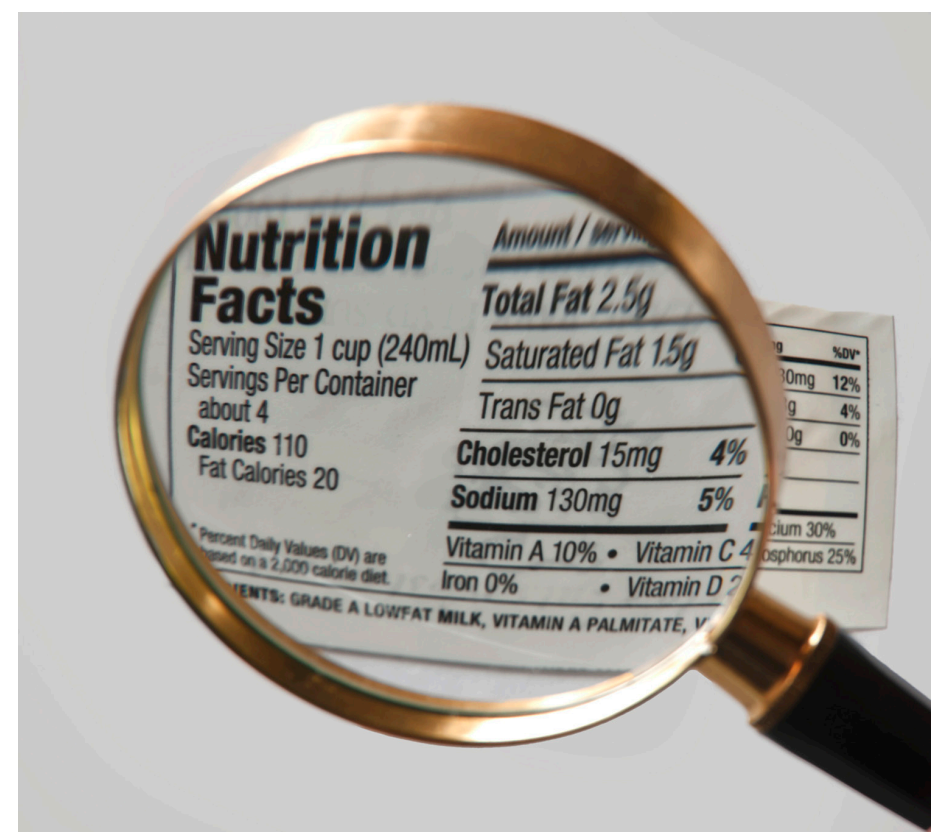

Figure 5. Since 2006, all food labels must identify the source of ingredients derived from eight major allergens, including milk and egg. Credits: iStockphoto

\section{Food Allergy or Intolerance?}

Food intolerances can be confused with food allergies. Although these two conditions present some of the same symptoms, important differences exist between them. Remember that a food allergy involves the immune system. Eating even a tiny amount of a food that contains an allergen can be life-threatening. In contrast, food intolerance occurs when you have a problem breaking down the food that you eat or you are sensitive to food additives or chemicals added to foods. For example, lactose intolerance occurs when someone lacks the enzyme necessary to digest the milk sugar called lactose. If you are intolerant to a food, eating that food can cause unpleasant side effects, but food intolerance is not life-threatening, and eating just a small amount of that food may not cause any ill effects (American Academy of Allergy, Asthma \& Immunology, 2011).

\section{Preventing an Allergic Reaction}

Follow these tips and suggestions to help your child avoid an allergic reaction (Mayo Clinic, 2011):

\section{- Know what your child is eating and drinking: Always} read food labels carefully. Look at the ingredients list for milk and egg proteins. Food labels are required to clearly identify ingredients derived from major food allergens including milk and egg. Remember, even trace amounts of milk or egg can cause an allergic reaction.
- Be cautious when eating out: Always keep in mind that your server or cook may not know if a food contains milk or egg proteins.

- Coordinate with your child's school: Work with school officials and teachers to create a safe environment for your child. Make sure the school staff knows which foods are unsafe for your child. Also, meet with the school nurse before the school year to talk about what to do in case of an allergic reaction.

- Tell your child's caregivers about your child's allergies: Communicate with babysitters and caregivers about your child's allergies so that they can check to make sure your child does not eat foods that will cause a reaction. Caregivers also need to know what to do in case an allergic reaction occurs and you are not there.

- Talk with the parents of your child's friends: If your child will be going to a party or having a sleepover with friends, alert other parents about your child's food allergy. Give suggestions about alternative ingredients to use when preparing foods and safe, allergen-free snacks.

- Be aware of cross-contamination: Even if a food does not have milk or egg in it, this does not necessarily mean it hasn't come into contact with milk or eggs. When preparing foods for children who are allergic to milk or eggs, always avoid using the same utensils or surfaces you used to prepare other foods.

\section{Summary}

Milk or egg allergies can have a negative effect on your child's health. An estimated $85 \%$ of children outgrow food-related allergies, especially those to cow's milk and egg (Thong \& Hourihane, 2004). This statistic, however, is not a guarantee. Knowing which foods and ingredients your child should avoid is an important step in preventing an allergic reaction.

Always alert caregivers and teachers about your child's allergies, and consult with your child's doctor about any concerns you may have as a parent. For more information about food allergies, see the EDIS publication FY1282/ FCS8997 - Raising Healthy Children: Food Allergies at http:// edis.ifas.ufl.edu/fy1282. 


\section{Recommended Resources}

To get more information about allergies, visit the following websites:

- The American Academy of Allergy, Asthma \& Immunology (http://www.aaaai.org/home.aspx) - This site contains information about food allergies, symptoms and diagnosis, and treatment and management. It also provides milk-free and egg-free recipes.

- Asthma and Allergy Foundation of America (http://www. aafa.org/) - This site contains information about food allergies, symptoms and diagnosis, and treatment and management.

\section{References}

American Academy of Allergy, Asthma \& Immunology. (2011). Food allergy versus food intolerance. Retrieved from http://www.aaaai.org/Aaaai/media/MediaLibrary/ PDF\%20Documents/Libraries/EL-food-allergies-vsintolerance-patient.pdf

American Academy of Allergy, Asthma, \& Immunology. (2012). Food allergies. Retrieved from http://www.aaaai. org/conditions-and-treatments/allergies/food-allergies.aspx

Asthma and Allergy Foundation of America. (2005a). Egg allergy. Retrieved from http://www.aafa.org/print. cfm $? \mathrm{id}=9 \& \mathrm{sub}=20 \&$ cont $=523$

Asthma and Allergy Foundation of America. (2005b). Milk allergy. Retrieved from http://www.aafa.org/display. cfm?id $=9 \&$ sub $=20 \&$ cont $=516$

Boyano-Martinez, T., Garcia-Ara, C., Diaz-Pena, J. M., \& Martin-Esteban, M. (2002). Prediction of tolerance on the basis of quantification of egg white-specific IgE antibodies in children with egg allergy. J Allergy Clin Immunol 110(2):304-9. doi: http://dx.doi.org/10.1067/ mai.2002.126081

Eggesbo, M., Botten, G., Halvorsen, R., \& Magnus, P. (2001). The prevalence of allergy to egg: A populationbased study in young children. Allergy 56(5):403-11. doi:10.1034/j.1398-9995.2001.056005403.x

Food allergy. (2012). In A.D.A.M. Medical Encyclopedia online. Retrieved from http://www.ncbi.nlm.nih.gov/ pubmedhealth/PMH0001820/
Food Allergy Initiative. (2012). Milk allergy. Retrieved from http://www.faiusa.org/page.aspx?pid=379

Gupta, R. S., Springston, E. E., Warrier, M. R., Smith, B., Kumar, R., Pongracic, J., \& Holl, J. L. (2011). The prevalence, severity, and distribution of childhood food allergy in the United States. Pediatrics 2128(1), e9-e17. doi:10.1542/ peds.2011-0204

Mayo Clinic. (2011). Food allergy: prevention. Retrieved from http://www.mayoclinic.com/health/food-allergy/ ds00082/dsection=prevention

Phillips, D. A., Chang, C. Y., Chalmers, C., \& Foster, J. (2012). Foods containing milk. Retrieved from http://www. fauquierent.net/allergy/allergy-milk.pdf

Thong, B. Y., \& Hourihane, J. O. (2004). Monitoring of IgE-mediated food allergy in childhood. Acta Paediatrica 93(6):759-64. doi: 10.1111/j.1651-2227.2004.tb03014.x

U.S. Food and Drug Administration. (2010). Food allergies: What you need to know. Retrieved from http://www.fda. gov/Food/ResourcesForYou/Consumers/ucm079311.htm 